\title{
A study to assess the effectiveness of teaching programme on round worm infestation among middle school children at a rural setting.
}

\author{
Mrs.G. Bhuvaneswari M.Sc(N) \\ (Saveetha College of Nursing, Saveetha University, India) \\ (Saveetha College of Nursing, Saveetha University, India)
}

\begin{abstract}
The magnitude of parasitic infestation among children constitutes a major public health problem in many parts of the world. In India, $87.5 \%$ of the sludge samples were positive with ascaris, toxocara, trichuris and hook worm. The poor standard of living includes improper disposal of faecal and other wastes, overcrowding, unhygienic health practices and poor environmental sanitation. All these lead to various experiences such as malnutrition and worm infestation. The aim of this study was to describe the effectiveness of teaching programme on round worm infestation among middle school children. Quasi experimental design (one group pre and post test)was employed. 100 samples were selected by Simple random technique by lottery method from vi and vii standard students of Hindu coronation middel school at Madhuranthagam. Pre test was conducted by using structured questionnaire to assess the knowledge on round worm infestation among middle school children. After seven days post test was conducted by same questionnaire. The data were analysed using descriptive statistics (frequency, percentage, mean, standard deviation and inferential statistics(chi-square). The data on pre test knowledge on round worm infestation among middle school children shows that out of 100 samples, 10\% had inadequate knowledge, $74 \%$ had moderately adequate knowledge, 16 were adequate knowledge on round worm infestation. The improvement of knowledge on round worm infestation of middle school children in post 25 (25\%) had moderate knowledge, 75 (75\%) had adequate knowledge, no one had inadequate knowledge. The results shows that their was improvement in overall in aspects of knowledge on round worm infestation at he level of $p<0.001$.
\end{abstract}

Keywords: round worm infestation, school children, teaching programme

\section{Introduction}

The magnitude of parasitic infestation among children constitutes a major public health problem in many parts of the world. In India, $87.5 \%$ of the sludge samples were positive with ascaris, toxocara, trichuris and hook worm. The poor standard of living includes improper disposal of faecal and other wastes, overcrowding, unhygienic health practices and poor environmental sanitation. All these lead to various experiences such as malnutrition and worm infestation. Helminthes infestations contribute significantly to the global burden of diseases in children especially in the tropical and sub-tropical regions. This might be due to the increased population and decreased environmental sanitation.

UNICEF (2010) had suggested that school drinking water and sanitation towards health and hygiene is globally recognized as a key intervention to promote children's right to health and clean environment and to influence a general change in health promotion behavior and attitudes. The human excreta of a sick child is a carrier of disease and the main focus on infection. It contains the disease agent which is transmitted to a new host through various channels such as water, finger, flies, soil and food. The environment is vast, but there are some important factors which should be controlled before any society can hope to reach optimal level of health, the minimal level of disease and the maximal span of human life. The hygienic disposal of fecal matter, providing safe water supply and adequate housing is way to reduce incidence of parasitic infestation.

In recent years the parasitologists, public health workers, international agencies such as WHO and Food Adulteration Organization (FAO) have recognized this and began to spend major part of their money to prevent parasitic diseases.The government of India has undertaken several accelerated programmes aimed at providing sources of safe water for a large number of villages and small towns.

Integrated Child Development Service (ICDS) is yet another programme which includes de-worming as one of the objectives in which they periodically de-worm children below six years in slum areas by administering anti-helminthic drugs.

\section{Need for the Study:}

Prevention is the key, but early intervention can improve the outcomes. The global strategy is health for all which move towards primary health care that can be possible only by encouraging the community participation 
and mobilizing the community resources and using appropriate technology for reducing the mortality and morbidity among children. .

WHO (1997) had estimated that about 1400 million people world wide are infected with any one of the three kinds of intestinal helminthes. They are round worm, hook worm and whip worm infestation. In that 200 million children suffer from diseases associated with these infestations.

At least $40 \%$ of the world's children in the school age group among them about 400 million are infested with intestinal worms. Their growth, nutrition and learning ability are adversely affected.

Intestinal worms constitute a public health and socio-economic problem due to lower environmental and imbalance nutritional situation, which can be the major causes for mortality in the world.

Chakma, et al., (2000) had estimated that nearly one fourth of the world's population harbor one or more intestinal worms in their intestinal tract. In India, the problem is likely to be more common because of poor hygiene, unawareness, and non literacy.

WHO (2002) had stated that the number of round worm infestation was 1450 in million in which mortality and morbidity rate was 350,65 million respectively.

To control these problems the community health nurse has a vital role. She is necessary to provide the preventive education to children and to their families regarding good hygiene and health habits such as proper hand washing before eating or handling food and after using the toilet etc.

The investigator observed in villages, many school going children with pot belly abdomen with malnutrition and they are suffering from abdominal pain, vomiting, diarrhea very often. Particularly the school children are more prone to get round worm infestation. So the investigator planned to conduct the study to assess the effectiveness of teaching programme on round worm infestation among middle school children at Maduranthagam, Kancheepuram District.

\section{Objectives:}

$>$ To assess the existing knowledge of Middle school children on round worm infestation.

$>$ To evaluate the effectiveness of teaching programme on round worm infestation among the middle school children.

$>$ To find out the association between pre and post test knowledge and the selected socio-demographic variables of middle school children on round worm infestation.

\section{Hypothesis:}

There will be significant difference in the knowledge among Middle school children on round worm infestations before and after the teaching programme.

\section{Delimitations}

$>$ The sample size was delimited to 100 students.

$>$ The study was delimited to children aged 11-13 years.

$>$ The study was delimited to rural setting.

$>$ Period of study was delimited to 6 weeks only.

\section{Research design:}

\section{Methodology:}

A quasi- experimental research design, one group pre test and post test was used for the study to assess the effectiveness of teaching programme on round worm infestation among middle school children.

\section{Setting :}

This study was conducted in Hindu Coronation Middle School at a rural setting in Maduranthagam, Kancheepuram district. Each class has two sections and has both boys and girls. There twenty teachers were working in the school. The school follows the State Government Syllabus. Total strength of the school is 836 . Out of this, 160 students are studying in VI \& VII standards (A \& B Sec). In that 100 students were selected for the study.

Population:

Variables :

All the school going children in the age group of 11-13 years.

Dependent variable - knowledge of middle school children

Independent variable - teaching programme

Socio-demographic variables - age, sex, educational status of the mother, educational status of the father, mother's occupation, father's occupatio, total income of the family per month, place of defecation, source of drinking water, source of heath information. 
Sample:

The sample refers to the age between 11 to 13 years of school going children from Hindu coronation middle school in Maduranthakam.

Sample size:

Sample size consists of 100 students, including 53 boys and 47 girls.

Sampling technique :

The samples were selected by using simple random sampling technique. Totally 160 students were in VI \& VII standard between age group of 11 to 13 years. Among them, 100 students were selected by using simple random sampling technique (Lottery method).

\section{Criteria for sample selection:}

Inclusion Criteria:

- Children those who were willing to participate

- $\quad$ Children of both the sexes

\section{Exclusion Criteria:}

- The children who were above 13 years \& below 11 years

- The children who were sick / absent on the day of study

\section{Development and description of the instrument}

By referring various text books and network the investigator had developed the questions and teaching programme on round worm infestation for Middle School Children. It was edited by the experts of various discipline namely, Medical professors, Nursing professors and Language experts. The corrections and suggestions were carried out. The tool was validated and reliable to do the study. The tool is consisting of following,

Part I : Consists of socio-demographic variables

Part II : Consists of structured questions related to round worm infestation

Part I

Socio - demographic data consists of age, gender, educational status of mother, educational status of father, mother's occupation, father's occupation, total income of the family per month, place of defecation, source of drinking water and source of health information.

Part II

A structured questionnaire to assess the knowledge on round worm infestation and knowledge on hygienic health practices. There were 10 multiple choice questions related to knowledge on round worm infestation regarding meaning, structure, causative organism, predisposing factors, mode of transmission, life cycle signs \& symptoms, diagnosis, treatment, complications and preventive measures and 15 dichotomous type of questions related to knowledge on hygienic health practices were included. The tool was prepared by reviewing the literature and by consulting experts.

\section{Scoring procedure:}

There were 10 multiple choice questions related to knowledge on round worm infestation and 15 dichotomous types of questions related to knowledge on hygienic health practices. The correct answer was given a score point of "one" and wrong answer score was "zero". The Maximum total score was 25.

\section{Scoring interpretation:}

The score were categorized as follows:

- Above 75\% - Adequate knowledge

- $51-75 \%$ - Moderately adequate knowledge

- Below 50\% - Inadequate knowledge

\section{Data collection procedure:}

Prior permission was obtained from the head master of the Hindu coronation middle school, Maduranthagam at kancheepuram district, through Principal College of Nursing, Saveetha University Chennai 77. The Children who met the inclusion criteria only selected for the study samples and purpose of the study was explained. On the first day the investigator was introduced to the group of 160 children from VI \& VII Standards (A \& B Sec) assigned for the study. 100 children were selected by simple random sampling technique. A questionnaire schedule regarding round worm infestation was used and respondents written response were marked by participant. Approximately 15-20 minutes was taken for each sample to collect the data through questionnaire method. On the same day a planned teaching programme was given to middle school 
children about 45 minutes by using adequate audio visual aids and 10 minutes was given for discussion. The data were collected after seven days by using same questionnaire schedule to find out the effectiveness of teaching progarmme. The same procedure was followed for all the 100 sample

\section{Data analysis and statistical methods used}

The items scored after pre and post test results were tabulated. The statistical method used for analysis includes number, percentage, mean, standard deviation, paired ' $\mathrm{t}$ ' test and chi- square test.

\begin{tabular}{|l|l|l|l|}
\hline S.no & Data analysis & Method & Remarks \\
\hline 1 & Descriptive statistics & Mean and standard deviation & $\begin{array}{l}\text { To assess the pre and post test knowledge on } \\
\text { round worm infestation among middle school } \\
\text { children. }\end{array}$ \\
\hline 2 & Inferential statistics & Paired 't' test & $\begin{array}{l}\text { To determine the effectiveness of teaching } \\
\text { programme on round worm infestation among } \\
\text { middle school children }\end{array}$ \\
\cline { 3 - 4 } & & Chi- square test & $\begin{array}{l}\text { to find out the association between the pre } \\
\text { and post test knowledge and selected socio- } \\
\text { demographic variables of the middle school } \\
\text { children. }\end{array}$ \\
\hline
\end{tabular}

\section{Results:}

Effectiveness of knowledge of middle school children on round worm infestation after teaching programme (paired' 't' test)

\begin{tabular}{|l|l|l|l|l|}
\hline \multirow{2}{*}{ Aspects of knowledge } & Improvements knowledge score & \multicolumn{2}{l|}{} \\
\cline { 2 - 5 } & Mean & $\begin{array}{l}\text { Standard } \\
\text { Deviation }\end{array}$ & Paired 't' test & p-value \\
\hline Round worm infestation & $\mathbf{2 1 . 7 0}$ & $\mathbf{2 4 . 9 9}$ & $\mathbf{8 . 6 8 4}$ & $\begin{array}{l}\text { P<0.001 } \\
\text { (significant) }\end{array}$ \\
\hline Hygienic health practice & $\mathbf{1 2 . 0 0}$ & $\mathbf{1 5 . 7}$ & $\mathbf{7 . 6 0 9}$ & $\begin{array}{l}\text { P<0.001 } \\
\text { (significant) }\end{array}$ \\
\hline Overall & 15.88 & 13.67 & 11.613 & $\begin{array}{l}\text { P<0.001 } \\
\text { (Significant) }\end{array}$ \\
\hline
\end{tabular}

Table shows the effectiveness of knowledge of middle school children on round worm infestation after teaching programme

The overall paired " $t$ " test value was significant at the level of $\mathrm{P}<0.001$. This shows that there was significant improvement in knowledge after the teaching programme on round worm infestation.

\section{Discussion:}

The aim of the present study was to assess the effectiveness of teaching programme on round worm infestation among middle school children at a rural setting.

A sample of 100 middle school children were selected by using simple random sampling technique. The pre test was conducted by using a structured questionnaire. After the pre - test the investigator planned teaching programme was given to the group of children by lecture cum discussion a structured teaching programme. The post - test was conducted on the eighth day by using the same instrument.

The first objective of the study was to assess the existing knowledge of middle school children on round worm infestation.

The assessment of the knowledge of the middle school children prior to the teaching programme helps to know clearly about the round worm infestation.

the assessment of existing knowledge of middle school children on round worm infestation out of 100 middle school children ten (10\%) children had inadequate knowledge 74 (74\%), had moderately adequate knowledge $16(16 \%)$ had adequate knowledge on round worm infestation in pre-test.

The present knowledge level of middle school children indicated that there was a need to improve the knowledge of the middle school children regarding round worm infestation by means of health education and teaching programme.

The above objective were supported by EDNA SWEENIE (2002), who had conducted a study to assess the effectiveness of structured teaching programme on round worm infestation among primary school children at Chennai. The results revealed that in pre-test 46 (92\%) children had inadequate knowledge, $4(8 \%)$ children had moderately adequate knowledge and none had adequate knowledge.

The second objective of this study was to determine the effectiveness of teaching programme on round worm infestation among middle school children. 
The teaching programme was a systematic approach. This helped to provide pertinent information regarding round worm infestation in a concise format. It helped the children develop knowledge and skill in round worm infestation.

The assessment of existing knowledge of middle school children on round worm infestation out of 100 middle school children ten (10\%) children had inadequate knowledge 74 (74\%), had moderately adequate knowledge $16(16 \%)$ had adequate knowledge on round worm infestation in pre-test.

The distribution of knowledge score of middle school children on round worm infestation in post test. Overall knowledge aspects, no one had inadequate knowledge 75 (75\%) children have gained adequate knowledge, 25 (25\%) children had gained moderately adequate knowledge.

The effectiveness of knowledge of middle school children on round worm infestation after teaching programme. The overall paired "t" test value was significant at the level of $\mathrm{P}<0.0012$. this shows that there was significant improvement in knowledge after the teaching progrmame on round worm infestation.

The third objective of the study was to find out the association between the pre and post test knowledge and selected socio - demographic variables on round worm infestation among middle school children.

There was no association between the level of knowledge and selected socio - demographic variables on round worm infestation. It was statistically found that, there was no association between the demographic variables namely age, sex, educational status of mother, education status of father, mother's occupation, father's occupation, total income of the family per month, source of drinking water, place of defecation and source of health information at $\mathrm{P}<0.05$ level.

There was no association between the level of knowledge and selected socio - demographic variables on round worm infestation. It was statistically found that, there was no association between the demographic variables namely age, sex, educational status of mother, education status of father, mother's occupation, father's occupation, total income of the family per month, source of drinking water, place of defecation and source of health information at $\mathrm{P}<0.05$ level.

\section{Recommendation}

1. As the structured teaching programme was effective in school children, similar teaching programme may be initiated in all schools.

2. School children should be motivated to use the health care services available in their area.

3. Mass Communication through regional language should be adapted to educate regarding round worm infestation in school children.

\section{Conclusion:}

The overall finding of the study revealed significant improvement in knowledge regarding round worm infestation. This type of educational programme could bring a change in awareness in round worm infestation. Hence the hypothesis stated at the beginning of this study is confirmed.

\section{(Books and journals)}

\section{References:}

[1]. Achar's (2002). Text book of Pediatrics madras: orient Longman.

[2]. Adelepillitteri (1999). Child health nursing (care of the child and family) Philadelphia : Lippincott

[3]. Ananymous, (1978). Unicef news, unicef: 4: 34.

[4]. Asaolu, so., et al. (2002). Effect of water supply and sanitation the prevalence and intensity of ascaris lumbricoides among pre school children in Nigeria, Journal of tropical medical hygine, 96(6): 600-4.

[5]. Bansal. D, et. al., (2004). Intestinal parasites and intra familial incidence in a low socio - economic area of Chandigarh Nepal, Journal of medical college; $6(1): 28-31$.

[6]. Basavanthapa, B.T (2003). Text book of Community health nursing Delhi: Lordson.

[7]. Bhondeley. MK., et al., (2002). worm infestation and anaemia among tribal preschool children of Madhya Pradesh, Journal of Communicable disease, 34(2) : $100-5$.

[8]. Chakraborty, M. et al., (2004). A study to assess the prevalence of parasitic infestation among school children, Journal india medical association, $102(7), 349-52$.

[9]. Chatarvedi R.M. and Kartikayan S. (WHO) world health Organisation, 1992: Volume 13.

[10]. Crompton D.W.T. (1992). Ascaries and childhood malnutrition, Journal of tropical medical hygiene, $86: 577-599$.

[11]. Dennis polit and F. Berbadette Nursing research principles and methods, Philerdelphia : lippincott.

[12]. Erdener A, et al., (1992). Abdominal complication of ascaris lumbricoides in children, Jama, 42: 73, 74.

[13]. Fung I.C et. al., (2008). Ascariasis and handwashing, Journal of tropical medical hygiene.

[14]. Gangopadhway A.N. (2007). Conservative treatment for round worm and intestinal obstruction in India, Journal of Pediatric, 74(12) : (1085-1087).

[15]. Jayaram panikar C.K (1994). Text book of medical parasitology Mumbai: Jayee.

[16]. Kabatereine. Et al., (2001). Epidemiology of intestinal helminthes infestation among school children in southern Uganda, Medial journal of East Africa, 78(6): $283-6$.

[17]. Kaur R, et al., (2002). Intestinal parasites in children with diarrhea in delhi, Journal of tropical medical public, 33(4):725 - 9,

[18]. Keiser J, et al., (2008). Efficacy of current drugs against soil - transmitted helminth infections, JAMA, 23; 299(16): 1937-48. 